\title{
Defining Sustainability In The Business Setting ${ }^{1}$
}

Justin Bateh, D.B.A., Florida State College at Jacksonville, USA

Camille Heaton, RTI International, USA

Gordon W. Arbogast, Ph.D., Jacksonville University, USA

Ardell Broadbent, Pepperdine University at West Los Angeles, USA

\begin{abstract}
Sustainability has become a buzzword in organizational research and ecological science. Much has been said about the role of sustainability for organizational development and markets. Thousands of organizations worldwide have adopted sustainability strategies to boost their productivity and develop a competitive advantage. Yet the concept of sustainability is so complex that it is virtually impossible to ensure a standardized definition or for one organization to understand all its facets in detail. Moreover, under the influence of its own popularity, the concept of sustainability constantly evolves and changes meaning. More often than not, organizations and leaders develop a narrow view of sustainability. They consider only the aspects of sustainability that are directly related to their sphere of performance. In this article, three elements of the definition of sustainability are discussed: longevity, maintenance of core principles or purposes, and responsibility to external needs. The term organization is used because the principles are often applicable to governmental and non-profit organizations as well as businesses.
\end{abstract}

Keywords: Organizational Sustainability; Accountability; Transparency

\section{INTRODUCTION}

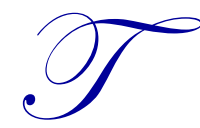

he current state of literature provides abundant information about the importance of sustainability in business and the most important sustainability trends. Business researchers constantly seek to link the notion of sustainability to other business-oriented concepts, including internalization, organizationspecific advantages, public policy, organizational strategy, competitiveness, and leadership (Kolk \& Pinkse, 2008). These researchers stimulate the debate within business about its role in promoting sustainability in society (Watson, Corbett, Boudreau, \& Webster, 2012). Meanwhile, researchers analyze the connections between sustainability and leadership, accountability, organizational change, and information technologies.

Despite the growing body of literature, numerous gaps in sustainability knowledge continue to persist. Researchers still lack any agreement as for the definition and notion of sustainability. According to Fibuch and Way (2012), "there are at least 50 definitions of sustainability in the literature" (p. 36). Current sustainability research could benefit from a single, universal definition of sustainability that could be used uniformly across various fields of business activity and research.

According to the root meaning of the word, a basic definition of organization sustainability must include longevity and retaining of core principles or purposes, regardless of internal and external changes over time. According to this definition, the long-term success of any organization greatly depends on the degree to which its sustainable development strategy is functional. Raatsch (2012) focuses on another element by choosing the sustainability definition provided by the Brundtland commission, which interprets sustainability as the process of development (or business activity) that satisfies the needs of today's generation without limiting or impeding the needs of later generations. As applied to business and organizational activities, organizations are expected to use

\footnotetext{
${ }^{1}$ This article is a reprint from the American Journal of Business Education May/June 2013, Volume 6, Number 3.
} 
scarce resources to satisfy their needs in ways that will enable future generations to satisfy these needs without greater difficulty than is imposed on the current generation. The present discussion is organized around these three elements of the definition of sustainability: longevity, maintenance of core principles or purposes, and responsibility to external needs.

\section{STATEMENT OF THE PROBLEM}

Despite the growing amount of literature on the topic, as well as the increasing awareness of sustainability issues in society, the current knowledge of business sustainability has many gaps and inconsistencies. Sustainability research is highly diverse and unsystematic. To some degree, different types of organizations face different sustainability needs. Even the meaning of the word sustainability varies greatly across organizations and researchers. In light of these controversies, the existing sustainability research needs to be systematized and reorganized, to reflect the most important sustainability and resource allocation issues facing today's organizations. A starting point for greater systematization and order is clarity in the definition of the concept, which the present article attempts to provide.

\section{LONGEVITY}

Unfortunately, many organizations and researchers limit their vision of sustainability to purely ecological strategies: for example, Albino, Balice, Dangelico, and Iacobone (2012) explored the impact of ecological strategies on green product development. This view does not fully address how to promote sustainability efforts in organizations whose focus does not relate to product development. In reality, the concept of sustainability and its impact on organizations' performance are much broader. Positive links between organizations' sustainable and economic performance have been widely established (Lee \& Pati, 2012). One of the most recent trends is a discussion of sustainability impacts on business and various aspects of organizational performance, including discussion of the importance of the competitive and cost-effectiveness potentials for sustainability measures. Lee and Pati insist that an organization's social and ecological performance are the best predictors of its economic and market-based performance results. The combined effects of both social and environmental performance on organizations' economic and market performance are particularly significant (Lee \& Pati, 2012).

\section{MAINTAINANCE OF CORE PRINCIPLES OR PURPOSES}

For businesses, making a profit is typically the core purpose. Many managers still take the stance that sustainability measures create no benefit unless they yield short-term financial profits. With this stance, they fail to recognize the potential benefits of sustainability measures for overall organizational performance (Fibuch \& Way, 2012). Analyzing the pros and cons of sustainability in business requires a new way of thinking about the desired outcomes (Epstein \& Yuthas, 2012). Traditional cost-benefit analysis may not reflect the needs for sustainability evaluation in their entirety. A whole range of impacts and consequences of sustainability strategies need to be considered, from the ecological impacts to changes in labor practices, society, and product responsibility (Epstein \& Yuthas, 2012), all of which affect public perception of an organization. Monetary costs and benefits alone cannot create the full picture of sustainability impacts on organizations. Unfortunately, most companies lack effective instruments and adequate knowledge to measure financial outcomes of sustainability measures (Epstein \& Yuthas, 2012).

\section{RESPONSIBILITY TO EXTERNAL NEEDS}

One could argue that contemporary Western society is organized around the value of self-interest. Economic principles and considerations of rationality and accountability largely govern societal thinking and decision making. During the 20th century, most Western countries operated on the principle that allocation of scarce resources among organizations and individuals should be based on free enterprise and an economic philosophy largely based on supply and demand (Watson et al., 2012). Decades of the industrial revolution and the human commitment to continued development and technical advancement have changed the planet to the extent that some scientists believe that extensive use of fossil fuels may have polluted the global ecosystem and changed the climate to a dangerous and irreversible extent (Watson et al., 2012). The growing popularity of sustainability theories and 
perspectives indicates an increasing recognition that competitive pricing as part of currently favored economic principles may not be the best way to distribute scarce resources fairly. The field of sustainability science and research is currently calling on businesses to shift the emphasis away from a purely profit driven economic perspective to consider the individual and organization as part of a system that is currently unsustainable. The main reason is that competitive economies do not account for "externalities, which represent costs absorbed by society rather than the producer" (Watson et al., 2012, p. 29). Arbogast and Thornton (2012) determined that companies who embrace sustainability will thrive and the companies that do not will be challenged. Their definition of sustainability is that a business must operate in a manner that does not leave a significant footprint on the environment.

\section{LEADERSHIP ROLE IN SUSTAINABILITY INITIATIVES}

Linking executive leadership and sustainability has already become commonplace. It is a new trend to train leaders on sustainability responsibilities. It is possible to assume that, as leaders usually direct organizational change, so can they inspire sustainability changes in their organizations. The debate, however, is in how far should leaders' sustainability responsibilities go and whether sustainability should become a fiduciary responsibility of senior leaders (Fibuch \& Way, 2012). In most cases, the answer to these questions is affirmative: one primary responsibility of leaders is to ensure dissemination of an organizational vision that includes sustainability principles, followed by structures and processes that will sustain long-term success (Fibuch \& Way, 2012) and responsiveness to needs external to the organization. Moreover, to achieve the desired level of sustainability, aspects of organizational performance could be monitored and improved. As part of sustainability efforts, leaders could work to mitigate the most egregious resource waste, create economic and/or social value, and if a for-profit business, also promote a long-term perspective of maintaining or expanding financial capital through non-exploitative measures (Fibuch \& Way, 2012). Leaders may successfully combine the features of traditional and sustainable entrepreneurship, which will move their organizations toward the desired sustainability goals (Kury, 2012).

\section{CONCLUSION}

All fields of business are subject to influences of these three parts of the sustainability concept. As the popularity of sustainability trends increases, many organizations and corporate sectors have faced pressure to increase sustainability measures. Sustainability concepts and goals have become extremely common among businesses and enterprises, and its scope constantly expands. Sustainability is likely to become a dominant trend. Sustainability is now widely accepted as one of the most important factors of organizational growth and development. According to Epstein and Yuthas (2012), few reliable methods exist for assessing the outcomes of sustainability measures. A solid basis for future research - in which managers and scholars can engage in a united effort for the sake of reconciling the existing differences in stakeholder and management assumptions about sustainability performance outcomes - could be assisted by clarifying the definition of sustainability. As the body of research on corporate sustainability constantly increases, educators do well to convey these three basic organizing elements to students, to (a) prepare new business leaders and personnel with a basis from which to categorize and understand sustainability issues and (b) to promote the emergence of new strategies for sustainability.

\section{AUTHOR INFORMATION}

Dr. Justin Bateh is an Assistant Professor of Business at Florida State College at Jacksonville, where he teaches leadership, management, operations, and statistics courses. Prior to joining Florida State College at Jacksonville, Dr. Bateh served for over a decade in several leadership positions at a private, national medical education firm. Dr. Bateh held the positions of Director of Operations, Associate Director of Operations, and Operations Manager. He also helped manage the firm's venture capital and private equity investments, working with companies under ownership to help develop, merge, reorganize, and restructure existing operational infrastructures to optimize revenue growth and create cost efficiencies. Dr. Bateh's scholarly research in business has been published in the American Journal of Business Education, Journal of International Education Research, and Journal of Management \& Information Systems. His research interests involve applying quantitative approaches to issues in leadership and management. He has a Doctor of Business Administration from Walden University, a Master of Business Administration from Nova Southeastern University, and a Bachelor of Business Administration from University of North Florida. E-mail: jbateh@fscj.edu (Corresponding author) 
Camille Heaton is a senior environmental manager at RTI International conducting environmental research related to international and national environmental management. She is Deputy Project Manager for a 10-year strategic partnership between RTI and Environment Agency-Abu Dhabi (EAD) providing technical environmental services. Ms. Heaton also serves as the Project Manager for a technical assistance and capacity building grant in Morocco that includes a solid waste focus. She provides advice on reviewing complex environmental studies, such as environmental impact assessments for large-scale development and industrial projects, and develops standard operating procedures and technical guidelines based on international best practices.

Gordon Arbogast. As a Colonel Gordon Arbogast served as Associate Director of Engineering \& Technology for the Defense Communication Agency (now Defense Information Systems Agency), as well as Head of the Department of Engineering at West Point. In the civilian world he was a Principal Scientist for the Contel Technology Center and Vice President of Systems Technology for Pacific Bell. At Jacksonville University he was Associate Dean of the Davis College of Business (DCOB) and the Graduate Chair. He is now a Department Chair in the DCOB and professor of management. In that capacity he teaches courses including business policy and strategy, operations management, and organizational leadership. He has published extensively, including articles on corporate sustainability, business ethics, and restoration of ecosystems. E-mail: garboga@ju.edu

Ardell Broadbent is a small business owner who is active in non-profit organizations promoting ecological sustainability in local government. She has an MA from Pepperdine University in psychology. She has developed and writes for websites on issues of global ecological change, health, and interpersonal relationships. Ms. Broadbent's areas of interest include education research and cultural change.

\section{REFERENCES}

1. Albino, V., Balice, A., Dangelico, R. M., \& Iacobone, F. A. (2012). The effect of the adoption of environmental strategies on green product development: A study of companies on world sustainability indices. International Journal of Management, 29(2), 525-538.

2. Arbogast, G. W., \& Thornton, B. A. (2012). Global corporate sustainability model. Journal of Sustainability and Green Business, 1. Retrieved from http://www.aabri.com/manuscripts/10732.pdf

3. Ballou, B., Casey, R. J., Grenier, J. H., \& Heiger, D. L. (2012). Exploring the strategic integration of sustainability initiatives: Opportunities for accounting research. Accounting Horizons, 26(2), 265-288.

4. Epstein, M. J., \& Yuthas, K. (2012). Analyzing sustainability impacts. Strategic Finance, 27-33.

5. Fibuch, E., \& Way, C. W. (2012). Sustainability: A fiduciary responsibility of senior leaders? Physician Executive Journal, 36-43.

6. Kolk, A., \& Pinkse, J. (2008). A perspective on multinational enterprises and climate change: Learning from “An Inconvenient Truth"? Journal of International Business Studies, 39(8), 1359-1378.

7. Kury, K. (2012). Sustainability meets social entrepreneurship: A path to social change through institutional entrepreneurship. IJBIT, 4(3), 64-70.

8. Lee, J., \& Pati, N. (2012). New insights on the operational links between corporate sustainability and firm performance in service industries. IJBIT, 4(3), 80-93.

9. Raatzsch, R. (2012). On the notion of sustainability. Inquiry, 55(4), 361-385.

10. Watson, R. T., Corbett, J., Boudreau, M. C., \& Webster, J. (2012). Computing ethics: An information strategy for environmental sustainability. Communications of the ACM, 55(7), 28-30. 